\title{
Human complement C7 and C9 in fetal and newborn sera
}

\author{
M. ADINOLFI and SUSAN E. BECK \\ From the Paediatric Research Unit, Guy's Hospital Medical School, London
}

\begin{abstract}
Adinolfi, M., and Beck, S. E. (1975). Archives of Disease in Childhood, 50, 562. Human complement $\mathrm{C7}$ and $\mathrm{C9}$ in fetal and newborn sera. Using specific immune sera, C7, C9, and C3 activator were detected in sera from human fetuses more than 16 weeks old and in newborn samples. Levels of C9 in cord sera ranged between 10 and $30 \%$ of those present in sera from adult subjects. The mean value of C3 activator was about half that in maternal blood. The mean level of C7 in newborns was nearly $70 \%$ of the amount in normal adults.
\end{abstract}

The availability of antibodies to specific components of human complement $(\mathrm{C})$ and the analysis of in vitro cultures of fetal tissues have made it possible to study the onset and site of synthesis of these proteins during fetal life (Adinolfi, 1972; Rosen, 1974). The studies of the ontogeny of complement so far published have shown that $\mathrm{C} 1$, C3, C4, and C5 are produced by the human fetus at an early stage of gestation (Adinolfi and Gardner, 1967; Adinolfi, Gardner, and Wood, 1968; Gitlin and Biasucci, 1969; Colten, 1972, Köhler; 1973).

We report preliminary results of our investigations on the presence and estimation of $\mathrm{C} 3$ activator, $\mathrm{C} 7$, and $\mathrm{C} 9$ in sera from human fetuses and newborns.

\section{Materials and methods}

Twenty-four samples of cord blood were collected by syringe from the umbilical vein. Blood from normal adult individuals was taken by venepuncture. Serum was separated from clotted blood as soon as possible and the samples stored at $-20^{\circ}$ for no more than 2 months before being used. Blood was also collected by cardiac puncture from 5 fetuses whose ages, calculated from crown-rump length, ranged between 14 and 25 weeks. Most of the fetuses were obtained from therapeutic abortions.

Immune serum against C3 activator (factor B) was obtained from Behringwerke (Marburg, Germany) and it was raised against one of the breakdown products of factor B. The rabbit immune sera against $\mathrm{C} 7$ and C9 were made by injection of precipitin lines cut from immunoelectrophoretic plates using anti-C7 and antiC9 (kindly donated by Dr. H. Y. Müller-Eberhard,

Received 9 December 1974.
U.S.A.). Both antisera gave only one line of precipitation when tested by double diffusion in agar gel.

The presence of C7 and C9 in fetal and newborn sera was investigated using double diffusion in agar gel. Levels of C3 activator and C7 were measured by the single radial diffusion method, using a minor modification of the technique described by Köhler and MüllerEberhard (1967). Levels of C7 were also estimated with the agarose plate technique (Lachman, Hobart and Aston, 1973) using guinea pig red cells and $C \overline{56}$ euglobulin prepared from sera collected from normal women after childbirth. Concentrations of C9 were estimated by comparing the patterns of precipitations of serial dilutions of a normal adult serum with those of fetal and newborn samples.

In the present paper the amount of $\mathrm{C} 3$ activator is expressed in $\mathrm{mg} / 100 \mathrm{ml}$, using a standard serum provided by Behringwerke (Marburg, Germany), and levels of C7 and C9 in fetal and newborn sera are expressed as a percentage of the amount detected in adult samples.

\section{Results}

C3 activator was detected in all 21 newborn samples tested and in sera from 5 fetuses of from 14 to 25 weeks of gestation. Individual levels of C3 activator in adult, cord, and fetal sera are shown in Fig. 1. The mean value of this protein in the newborn samples was $8.49 \mathrm{mg} / 100 \mathrm{ml}$. Levels of C3 activator were estimated in 2 fetal sera $(3 \cdot 7$ and $1.5 \mathrm{mg} / 100 \mathrm{ml}$ ), the youngest fetus being 16 weeks old; in the other 3 sera the protein was detected but the levels could not be measured being less than $1 \mathrm{mg} / 100 \mathrm{ml}$.

Using double diffusion in agar gel, C7 was detected in all newborn sera tested. When levels of 


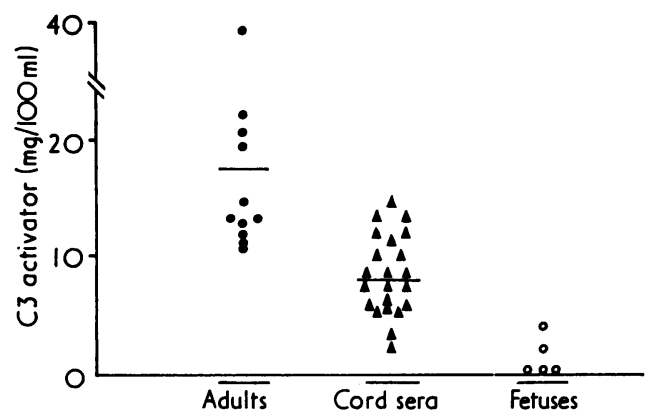

FIG. 1.-Levels of C3 activator (in $\mathrm{mg} / 100 \mathrm{ml}$ ) in sera from normal adults, cord sera, and sera from fetuses between 14 and 25 weeks of age. In 3 fetuses C3 activator was detected by double diffusion but could not be estimated since the concentrations were lower than $1 \mathrm{mg} / 100 \mathrm{ml}$.

C7 in cord sera were estimated using the single radial diffusion technique, the areas of precipitation were occasionally ill defined in some plates. Nevertheless, levels of C7 ranged between 54 and 120\% of the mean level of pooled serum from normal adults. C7 was detected in 3 fetal sera tested by double and single radial diffusion techniques. The youngest fetus in which $\mathrm{C} 7$ was detected was 16 weeks old.

C7 was also estimated by the agarose plate technique using $\mathrm{C} \overline{56}$ euglobulin; the mean level of C7 in 14 cord samples was $67.3 \%$ of the mean value detected in adult sera. In the 5 fetuses tested, aged from 14 to 25 weeks, C7 levels ranged between 20 and $56 \%$ of the normal mean concentration (Fig. 2).

C9 was detected in 11 newborn sera out of 24 tested by double diffusion in agar gel; in the remaining 13 sera, the concentration appeared to be lesss than $5 \%$ of the levels in normal adult samples. By comparing the lines of precipitation obtained using several dilutions of an adult serum, C9 levels

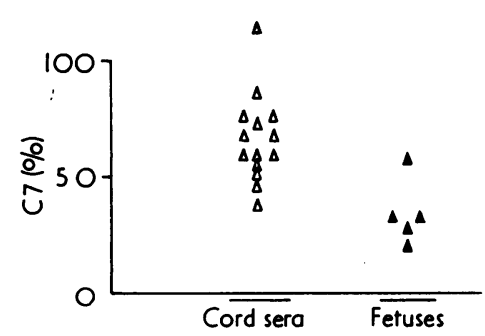

FIG. 2.-Levels of C7, expressed as percentage of the amount in sera from normal adults, in 14 cord sera and 5 fetuses. Estimation of C7 was carried out using the agarose plate technique. in the 11 cord samples were found to range between 5 and $50 \%$ of those present in normal adults (Fig. 3). C9 was also detected in sera from 3 fetuses aged 18, 20, and 25 weeks, but was not observed in 2 sera from fetuses 14 and 16 weeks old.

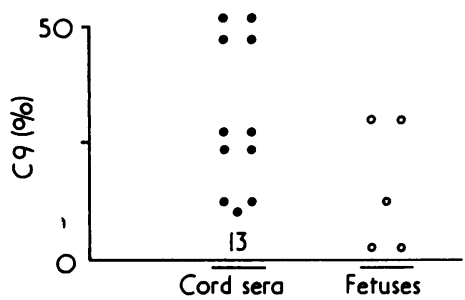

FIG. 3.-Levels of C9, expressed as percentage of the amount in sera from normal adults, in 24 cord sera and 5 fetuses. In 13 cord sera and 2 fetuses protein could not be detected using precipitation in agar gel.

\section{Discussion}

In recent years direct evidence that $\mathrm{C} 1, \mathrm{C} 3, \mathrm{C} 4$, and $\mathrm{C} 5$ are produced in utero has been obtained by analysis of the culture fluids of human fetal tissues incubated in media containing labelled amino acids. The presence in the culture fluids of newly synthesized specific components of complement was then established by the detection of haemolytically active proteins or by autoradiography of immunoelectrophoretic plates (Adinolfi, 1972; Rosen, 1974). Fetal synthesis of $\mathrm{C} 3$ and $\mathrm{C} 6$ has also been shown by detection of different genetic variants of these components of complement in pairs of maternal and cord sera (Propp and Alper, 1968; Alper, Hobart, and Lachmann, 1975).

In the present study, C3 activator, C7, and C9 were detected in newborn sera and in sera from fetuses over 16 weeks of age. The mean levels $o$ C3 activator in newborn samples was about half the mean value detected in adult sera, agreeing with the ratios between cord and adult sera observed for C3, C4, and C5 (Fireman, Zuchowski, and Taylor, 1969; Adinolfi, 1972). However levels of C9 in cord sera seem to be lower than those present in normal adults.

Detection of C3 activator, C7 and C9 in sera from human fetuses and from newborn infants agrees with studies on the ontogeny of the late components of complement in other mammals. Geiger, Day and Good (1972a, b) have detected C3 activator, C6, C7, C8, and $\mathrm{C} 9$ in fetal piglets. Haemolytically active C3, C6, and C7 were observed in sera from pig fetuses at an early stage of embryonic life in low titres, but showed a striking 
increase at about 110 days of gestation. By contrast, levels of $\mathrm{C} 8$ and $\mathrm{C} 9$ were found to increase regularly during embryonic life. Development of C3 activator appeared to precede the synthesis of $\mathrm{C} 3$. Early synthesis of components of complement has also been shown in fetal lambs, mice, and rabbits (Rice and Silverstein, 1964; Tachibana and Rosenburg, 1966; Adinolfi, 1972; Rosen, 1974).

Work is now in progress to determine the site of synthesis of C7 and C9 in human fetal tissues, using in vitro cultures. Preliminary data suggest that $\mathrm{C} 7$ is synthesized in the fetal liver.

We thank Dr. H. J. Müller-Eberhard for help. This work was supported by the Spastics Society and the M.R.C.

\section{REFERENCES}

Adinolfi, M. (1972). Ontogeny of components of complement and lysozyme. Ontogeny of Acquired Immunity, p. 65 . Ciba Foundation Symposium. Associated Scientific Publishers, Amsterdam.

Adinolfi, M., and Gardner, B. (1967). Synthesis of $\beta 1 E$ and $\beta 1 \mathrm{C}$ components of complement in human foetuses. Acta Paediatrica Scandinavica, 56, 450.

Adinolfi, M., Gardner, B., and Wood, C. B. S. (1968). Ontogenesis of two components of human complement: $\beta 1 \mathrm{E}$ and B1C-1A globulins. Nature, 219, 189.

Alper, C. A., Hobart, M. J., and Lachmann, P. J. (1964). Polymorphism of the 6th component of complement. Isoelectric Focusing, p. 306 . Ed. by J. P. Arbuthnott and J. A. Beeley. Butterworths, London.

Colten, H. R. (1972). Ontogeny of the human complement system: in vitro biosynthesis of individual complement components by fetal tissues. Fournal of Clinical Investigation, 51, 725.

Fireman, P., Zuchowski, D. A., and Taylor, P. M. (1969). Development of human complement system. Fournal of Immuno$\log y, 103,25$.

Geiger, H., Day, N., and Good, R. A. (1972a). Ontogenetic development and synthesis of hemolytic C8 by piglet tissues. Fournal of Immunology, 108, 1092.

Geiger, H., Day, N. K. B., and Good, R. A. (1972b). The ontogenetic development of the later complement components in fetal piglets. Fournal of Immunology, 108, 1098.

Gitlin, D., and Biasucci, A. (1969). Development of $\gamma \mathrm{G}, \gamma \mathrm{A}, \gamma \mathrm{M}$, $\beta 1 C, \beta 1 A, C ' 1$ esterase inhibitor, ceruloplasmin, transferrin, hemopexin, haptoglobin, fibrinogen, plasminogen, $\alpha 1$-antitrypsin, orosomucoid, $\beta$-lipoprotein, $\alpha 2$-macroglobulin, and prealbumin in the human conceptus. Fournal of Clinical Investigation, 48, 1433.

Lachmann, P. J., Hobart, M. J., and Aston, W. P. (1973). Complement technology. Handbook of Experimental Immunology, 2nd ed. Ed. by D. M. Weir, Blackwell, Oxford.

Köhler, P. F. (1973). Maturation of the human complement system. Fournal of Clinical Investigation, 52, 671.

Köhler, P. F., and Müller-Eberhard, H. J. (1967). Immunochemical quantitation of the third, fourth and fifth components of human complement; concentrations in the serum of healthy adults. Fournal of Immunology, 99, 1211.

Propp, R. P., and Alper, C. A. (1968). 'C'3 synthesis in the human fetus and lack of transplacental passage. Science, 162, 672.

Rice, C. E., and Silverstein, A. M. (1964). Hemolytic complement activity of sera of fetal and newborn lambs. Canadian fournal of Comparative Medicine and Veterinary Science, 28, 64.

Rosen, F. S. (1974). Complement: ontogeny and phylogeny. Transplantation Proceedings, 6, 47.

Tachibana, D. K., and Rosenburg, L. T. (1966). Fetal synthesis of Hc', a component of mouse complement. Fournal of Immuno$\log y, 97,213$.

Correspondence to Dr. M. Adinolfi, Paediatric Research Unit, Guy's Hospital Medical School, Cameron House, Guy's Hospital, London SE1 9RT. 